\title{
The Mechanism of Addition of Diazo-alkanes to Cyclopropanones
}

\author{
By Nicholas J. Turro* and Robert B. Gagosian \\ (Chemistry Department, Columbia University, New York, New York 10027)
}

Summary The addition of diazo-alkanes to cyclopropanones yields cyclobutanones whose structures may be predicted on the basis of conformational regulation of the migrating carbon-carbon bond.

THE addition of diazomethanes to cyclic ketones has recently been reviewed. ${ }^{1}$ The major products are derived from ring expansion to produce a homologous cyclic ketone or an epoxide. The mechanism of the ring expansion reaction is commonly considered as (a) nucleophilic addition of the diazomethane to the carbonyl carbon to form a zwitterionic intermediate ${ }^{\mathbf{1}, \mathbf{2}}$ followed by (b) 1,2-nucleophilic displacement of nitrogen by the electrons of a carboncarbon bond.1,2 Although the migration aptitudes which govern other 1,2-nucleophilic rearrangements ${ }^{3}$ appear to operate in the diazo-alkane ring expansion of cycloalkanones, an unusual migratory aptitude has been found for acyclic carbonyl compounds, ${ }^{4}$ in which the stereochemical factors which may control or modify reaction pathways are not easily assessable. We report here our results on the addition of diazoethane to trimethylcyclopropanone, for which the stereochemistry ${ }^{5}$ of the initial step (a) and the conformation of the resulting zwitterionic intermediate determine which $\mathrm{C}-\mathrm{C}$ bond migrates in step (b). These results represent the first experimental examination of the stereochemistry of the migrating and displaced centres in a diazo-alkane ring expansion of a cycloalkanone.

Treatment of 2,2,3-trimethylcyclopropanone, ${ }^{6}$ (1), with diazoethane yields the cyclobutanones $(2 \mathrm{c})$ and $(3 \mathbf{c})$ in $80 \%$ yield. ${ }^{7}$ Equilibration studies demonstrate that (2c) is clearly a kinetic product since none of the more stable epimer (2t) is formed under the reaction conditions, while (3c) is probably the kinetic and thermodynamic product. ${ }^{8}$ The free-energy difference between (2c) and (2t) was calculated to be $\Delta F=-0.71 \pm 0.07 \mathrm{kcal} . / \mathrm{mole}$.

Nucleophilic attack by the diazoethane from the most hindered side of $(\mathbf{1})$ appears unfavourable because of the steric crowding which would result. If we assume that attack from the less hindered side of (1) occurs and that the orientiation of the diazoethane leads to (4) (favoured) and to (5) (less favoured), we can explain the stereochemical course of the ring expansion to $(2 \mathrm{c})$ and (3c) (Scheme). Models indicated that the most favourable conformation of (4) is (4a). Rear-side displacement of nitrogen from this

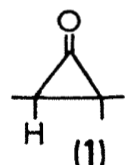

(1)

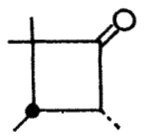

$(2 t)$

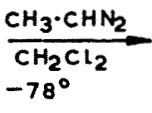

$-78^{\circ}$

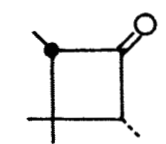

$(3 t)$

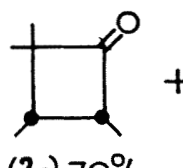

(2c) $70 \%$

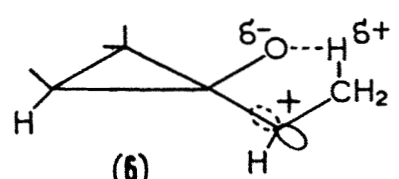

conformation yields the major product (2c). Rear-side displacement from unfavourable conformer (4b) would yield (3t), a product which is indeed not observed. Furthermore, the most favoured conformation of (5) is (5a), which
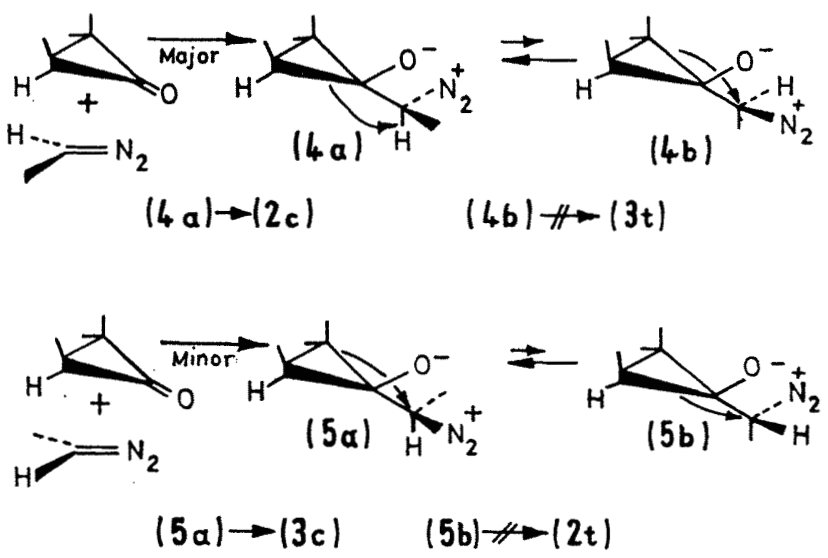

should be the precursor of $(3 c)$, as is found. Finally, the less favoured conformer (5b) should lead to $(\mathbf{2 t})$ which could not be detected in the reaction mixture. 
The less nucleophilic $\mathrm{C}-\mathrm{C}$ bond migrates preferentially in this reaction, in contrast to the ring expansion reactions of cyclopropanones and diazomethane (a symmetrical addend) for which the most nucleophilic $\mathrm{C}-\mathrm{C}$ bond migrates preferentially..$^{9,10}$

An alternative mechanism would involve product formation via the carbonium-ion intermediate, (6). However, in this case preferential migration of the most substituted bond is expected, in contradiction to the observed results.
Preliminary results on the stereochemistry of the addition of diazoethane to methylcyclopropanone are in agreement with the mechanistic picture presented here. ${ }^{.1}$

We thank Professor J. M. Conia and Dr. J. L. Ripoll for their comments and discussion of this work. We thank the Air Force Office of Scientific Research for their support of this work and we acknowledge a gift from the Upjohn Company. One of us (R. G.) was a Ferguson Teaching Fellow 19e8-69.

(Received, May 28th, 1969; Com. 741.)

1 C. D. Gutsche and D. Redmore, "Carbocyclic Ring Expansion Reactions," Academic Press, New York, 1968, p. 81.

2 (a) C. D. Gutsche, Org. Reactions, 1954, 8, 364; (b) C. Djerassi, B. F. Burrows, C. G. Overberger, T. Takekoshi, C. D. Gutsche, and C. T. Chang, J. Amer. Chem. Soc., 1963, 85, 945.

3 Ref. 2, pp. 3 and 61; A. Stretiwieser, "Solvolytic Displacement Reactions," McGraw-Hill, New York 1962; D. Bethell and V. Gold "Carbonium Ions," Academic Press, New York, 1967; E. R. Thornton, "Solvolysis Mechanisms," Ronald Press, New York, 1964.

4 H. O. House, E. J. Grubb, and W. F. Gannon, J. Amer. Chem. Soc., 1960, 82, 4099.

3 For recent work on this aspect of the reaction, see J. A. Marshall and J. J. Partridge, J. Org. Chem., 1968, 33, 4090.

- Prepared by the addition of diazoethane to dimethylketen. See N. J. Turro, Accounts Chem. Res., 1969, 2, 25 and references therein.

7 Compounds $(2 \mathrm{c}), 2 \mathrm{t})$, and $(\mathbf{3 c})$ were characterized unambiguously by their spectral properties. Compounds $(2 \mathrm{c})$ and $(\mathbf{2 t})$ were shown to be identical to authentic material by comparison of spectra kindly provided to us by Professor J. M. Conia: see H. Audier, J. M. Conia, M. Fetizon, and J. Gore, Bull. Soc. chim. France, 1964, 787.

8 The greater stability of $(\mathbf{3 c})$ as compared with $(\mathbf{3 t})$ is apparently a consequence of the nonplanarity of the cyclobutanone ring structure: J. M. Conia, J. L. Ripoll, K. A. Tushaus, C. L. Neumann, and N. L. Allinger, J. Amer. Chem. Soc., 1962, 88, 4982; J. M. Conia and G. Gore, Bull. Soc. chim. France, 1964, 1968.

- For similar arguments used to explain the product ratios formed in the ring expansion of cyclohexanones by diazomethane see: C. D. Gutsche, H. F. Strohmager, and J. M. Chang, J. Org. Chem., 1958, 23, 1; R. G. Carlson and N. S. Behn, ibid., $1968,33,2069$.

${ }_{10}$ N. J. Turro and W. B. Hammond, Tetrahedron, 1968, 24, 6017.

11 R. B. Gagosian and N. J. Turro, unpublished results. 